\title{
Measuring and Modeling the Plasticity of Clays
}

\author{
Fernando Augusto de Andrade, Hazim Ali Al-Qureshi, Dachamir Hotza* \\ Núcleo de Pesquisa em Materiais Cerâmicos - CERMAT, \\ Departamentos de Engenharia Mecânica - EMC e Engenharia Química - ENQ, \\ Universidade Federal de Santa Catarina - UFSC, \\ CEP 88040-900, Florianópolis, SC, Brazil
}

Received: April 1, 2010; Revised: June 29, 2010

\begin{abstract}
The measurement of plasticity in clay bodies is crucial in order to get products free of defects and with less processing time. However, tests which simulate the behavior of the clay during processing and the mathematical modeling of some of its characteristics, particularly the plasticity, become difficult because many variables are involved and there is no consensus on the choice of method to be used. This study aimed to develop a mathematical model based on compression test to evaluate the plasticity of clays. Three types of clays were studied with different levels of moisture and their indices of plasticity were also characterized by the Atterberg's and Pfefferkorn's methods. The experimental data were well fitted by the theoretical curves for a wide range of clay plasticity. Moreover, it was possible to observe a correlation between effective stress of compression and paste moisture within each group of clay.
\end{abstract}

Keywords: clays, extrusion, plasticity, modeling

\section{Introduction}

The plasticity in the processing of ceramic materials is a fundamental property since it defines the necessary technical parameters to convert a particulate ceramic body to a component with a given shape by application of pressure.

The plasticity, in this case, and particularly in clay mineral systems, is defined as a property that shows shape changes without rupture when a clay body with added water is submitted to an external force. Furthermore, when the force is removed or reduced below to a value corresponding to the yield stress the shape is maintained ${ }^{1}$.

The main factors that affect the clay plasticity, according to Barba et al. ${ }^{2}$ and Händle ${ }^{3}$, are related to physical characteristics of the solid, particularly the particle size distribution and its specific surface area, the water characteristics (viscosity, surface tension, etc.), the solid mineralogical composition (clay mineral type, proportion of nonplastic minerals, etc.), the dispersion state of the particles that depends on the ionic change capacity and nature and proportion of additives, as well as on the ceramic body temperature. Relevant process-related factors affecting clay plasticity are application of pressure, body temperature and characteristics of additives used ${ }^{4}$.

However, the plasticity determination is not always an easy task since it cannot be immediately applied and interpreted. In fact, there are several methods for measurement and characterization of the plasticity of a clay body, although its experimental determination, in some cases, is operator-dependent, causing difficulties in interpreting the results ${ }^{5}$. Among the methods, the Atterberg's plasticity index, the Pfefferkorn's plasticity index, stress/strain curves, indentation and rheological measurements are the most applied.

The Atterberg's plastic limit is the lowest water content at which the body can be rolled into threads without breaking. The Atterberg's liquid limit is the water content at which the body begins to flow, using a specific apparatus. The difference between both values is called the Atterberg's plasticity index ${ }^{6}$. Alternatively, the Pfefferkorn method determines the amount of water required to achieve a $30 \%$ contraction in relation to the initial height of a test body under the action of a standard weight ${ }^{\text {. }}$.

As with other types of materials, a compression test can be used to evaluate the plasticity of clays. Baran et al. ${ }^{8}$ formulated their workability concept for clays using compression tests in cylindrical samples, allowing to determine the optimum amount of moisture for each clay studied. Ribeiro et al. ${ }^{5}$ evaluated the plasticity of extrudable clays by compression tests and found that the measured samples were ruptured at 50-55\% deformation. In a typical test curve, a great deal of information is obtained: modulus of elasticity, yield strength, maximum deformation and rupture strength. Those parameters are strongly influenced by the moisture of the clay and its chemical or phase composition.

Clays may present a wide range of plasticity values ${ }^{9}$. Typical values of Atterberg's plasticity index for Kaolinitic clays range from 5 to 22 ; for ilittic clays, from 39 to 51 ; and for montmorillonitic clays, up to $600 .^{2}$

Usually measurements of clay plasticity are undertaken without considering a formal description of this physical behavior through a modeling approach. A model would not only describe the process in a broader and deeper way, but it also might be used for predicting a system's behavior with a lower experimental effort.

In this paper, a mathematical model for evaluation of the plasticity of clay bodies was developed from applied concepts of the plasticity theory by using the stress/strain diagram under compression.

\section{Mathematical Modeling of Compression Test}

The mathematical knowledge applied to metallic porous materials was used as a basic tool for plasticity modeling of clays ${ }^{10}$ taking into account few experimental parameters.

To define the processing parameters, it was assumed that the clay compact, which has a cylindrical shape, deforms axially and symmetrically. When the compressive force is applied, the height 
of the cylindrical compact decreases and its instantaneous radius increases since the sample is not confined in a die. Considering an infinitesimal volume in cylindrical coordinates $(r, \theta$ e $z)$ and the equilibrium of forces ${ }^{10}$ (Figure 1) in the radial direction $r$, it results in Equation 1:

$$
\frac{\partial \sigma_{r r}}{\partial r}+\frac{1}{r} \frac{\partial \sigma_{\theta r}}{\partial \theta}+\frac{1}{r}\left(\sigma_{r r}-\sigma_{\theta \theta}\right)+F_{r}=0
$$

In this model the compressive stress is assumed constant and for the shape of the infinitesimal volume studied, Equation 1 is simplified (Equation 2):

$$
\frac{d \sigma_{r}}{d r}+\frac{\left(\sigma_{r}-\sigma_{\theta}\right)}{r}=\frac{-2 \mu \sigma_{z}}{h}
$$

where $\sigma_{r}$ is the radial stress; $\sigma_{\theta}$, the normal stress; $\sigma_{z}$, the axial stress; and $\mu$, the coefficient of friction between plates surfaces of the compression test machine and the clay compact. The coefficient of friction is also considered constant and will be discussed later.

As $\sigma_{r}=f\left(\sigma_{\theta}\right)$ and using the Levy-Mises equations ${ }^{11}$ for the plastic zone, results in $\mathrm{d} \varepsilon_{r}=\mathrm{d} \varepsilon_{\theta}$ and, consequently, $\sigma_{r}=\sigma_{\theta}$. By substituting in Equation 2 the Equation 3 is obtained:

$$
\frac{d \sigma_{r}}{d r}=-\frac{2 \mu \sigma_{z}}{h}
$$

By using the Mises criteria ${ }^{11}$ related to the effective stress in compression $\bar{\sigma}$ of the clay material, the Equation 4 is obtained:

$$
\sigma_{r}=\sigma_{z}+\bar{\sigma}
$$

Deriving Equation 4 and substituting it into Equation 3 reduces to Equation 5:

$$
\frac{d \sigma_{z}}{d r}=-\frac{2 \mu \sigma_{z}}{h}
$$

To solve the differential Equation 5, the following boundary conditions are considered (Equations 6 and 7):

$$
\begin{aligned}
& r=r_{f} \\
& \sigma_{z}=-\bar{\sigma}
\end{aligned}
$$

where $r_{f}$ is the final radius of the sample after compaction.

The resulting equation for the instantaneous axial stress as a function of the compaction processing parameters is given by (Equation 8):

$$
\sigma_{z}=-\bar{\sigma} \exp \left[\frac{2 \mu}{h}\left(r_{f}-r\right)\right]
$$

Knowing that the axial force in any compression stage is a function of the axial stress and the instantaneous area, it can be directly calculated by the Equation 9:

$$
F=\int_{0}^{r_{f}} 2 \pi \sigma_{z} d r
$$

Finally, from Equations 8 and 9 it is possible to relate the applied pressure to the compact instantaneous radius as well as to different variable types that affect the plasticity of a given ceramic body. Thus, a more accurate approach to obtaining ceramic bodies with optimized plasticity for a given application is expected.

\section{Materials and Methods}

Three clays supplied by Paraná Mineração (Brazil), called respectively A1, A2 and A3, were selected. Chemical and phase composition were determined, respectively, by X-ray Fluorescence (XRF, Philips PW 2400) and X-ray Diffractometry (XRD, Philips Xpert, $\mathrm{Cu} \mathrm{K} \alpha$ ).

Tests were performed for each clay to measure Atterberg's liquid limit (LL), according to the NBR $6459^{12}$, and plastic limit (PL),
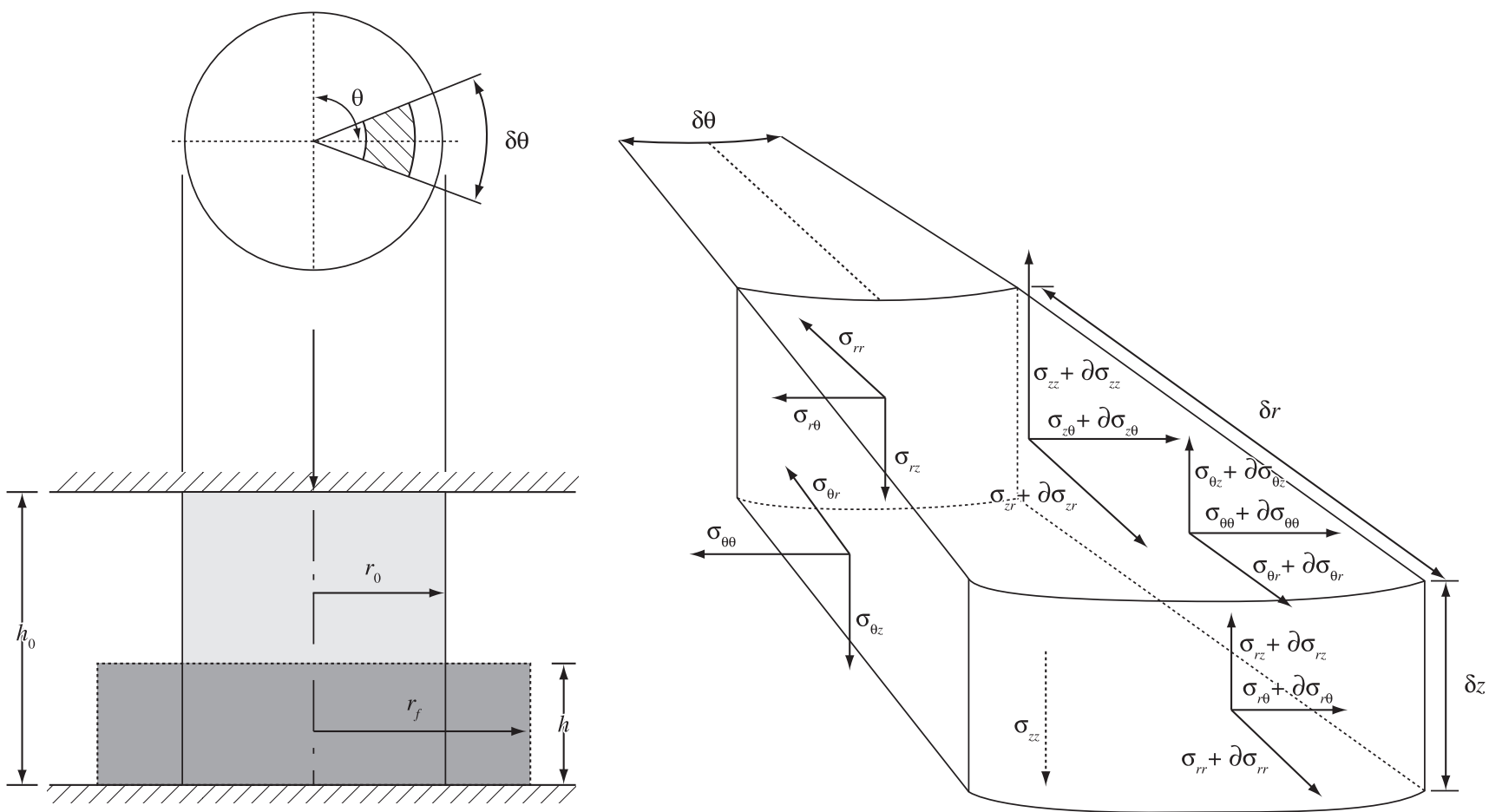

Figure 1. Process of compression of a clay cylinder and infinitesimal volume analysis of test specimen. 
Table 1. Chemical composition of the clays.

\begin{tabular}{cccccccccccc}
\hline Oxide $(\%)$ & $\mathrm{SiO}_{2}$ & $\mathrm{Al}_{2} \mathrm{O}_{3}$ & $\mathrm{Fe}_{2} \mathrm{O}_{3}$ & $\mathrm{CaO}$ & $\mathrm{Na}_{2} \mathrm{O}$ & $\mathrm{K}_{2} \mathrm{O}$ & $\mathrm{MnO}$ & $\mathrm{TiO}_{2}$ & $\mathrm{MgO}_{2}$ & $\mathrm{P}_{2} \mathrm{O}_{5}$ & $\mathrm{LoI}$ \\
\hline $\mathrm{A} 1$ & 62.83 & 22.86 & 2.39 & 0.02 & 0.07 & 1.10 & 0.06 & 1.36 & 0.57 & 0.06 & 9.26 \\
$\mathrm{~A} 2$ & 61.57 & 25.08 & 0.38 & 0.02 & 0.01 & 0.48 & 0.01 & 0.42 & 0.13 & 0.05 & 8.37 \\
$\mathrm{~A} 3$ & 52.45 & 33.43 & 0.73 & 0.00 & 0.01 & 0.27 & 0.01 & 2.11 & 0.10 & 0.06 & 13.33 \\
\hline
\end{tabular}

LoI: Loss on ignition at $1000{ }^{\circ} \mathrm{C}$.

Table 2. Phase distribution of the clays.

\begin{tabular}{crrr}
\hline Phase $(\%)$ & A1 & A2 & A3 \\
\hline Kaolinite & 57.9 & 63.5 & 84.6 \\
Quartz & 35.9 & 32.0 & 13.0 \\
Accessories & 6.2 & 4.5 & 2.4 \\
\hline
\end{tabular}

Table 3. Atterberg's and Pfefferkorn's plasticity parameters.

\begin{tabular}{|c|c|c|c|c|}
\hline \multirow[t]{2}{*}{ Clay } & \multicolumn{3}{|c|}{ Atterberg } & \multirow{2}{*}{$\frac{\text { Pfefferkorn }}{\text { PPI }(\%)}$} \\
\hline & Liquid limit (\%) & Plastic limit (\%) & API $(\%)$ & \\
\hline A1 & 64.4 & 44.0 & 20.4 & 47.1 \\
\hline $\mathrm{A} 2$ & 44.6 & 30.9 & 13.7 & 37.9 \\
\hline A 3 & 72.6 & 42.8 & 29.8 & 53.0 \\
\hline
\end{tabular}

according to the NBR $7180^{13}$. The preparation of powder samples for both tests followed the NBR $6457^{14}$. Pfefferkorn's plasticity index was determined in a plasticimeter (Servitech CT-283) according to the method described by Amorós et al. ${ }^{7}$. In this work, both measurements were applied to estimate the lower and upper moisture amount to be added to the clay to promote a suitable workability.

For each combination of moisture from the clay-water system, their behavior in a uniaxial compression test was evaluated in order to obtain the data of effective compressive stress and also the coefficient of friction, which were applied to the theoretical model developed.

The clays were disaggregated in a dry ball mill for 25 minutes and then sieved through a mesh of $420 \mu \mathrm{m}$. After that, to determine the moisture content in the clays, samples containing $10 \mathrm{~g}$ of material were placed in the oven at $110 \pm 5^{\circ} \mathrm{C}$ for 24 hours.

Three values of moisture in the range between LL and (PL+LL)/2 (obtained from the Atterberg's test) were selected. The respective samples were then prepared and homogenized by hand mixing and then left to settle for 24 hours in a hermetically sealed container for homogenization of moisture. In a later stage, cylindrical specimens were manually prepared in PVC molds with a $17 \mathrm{~mm}$ diameter and $23 \mathrm{~mm}$ height.

The samples were then subjected to the uniaxial compression test in a texturometer (Stable Micro Systems TA-XT2i), with test speed of $0.1 \mathrm{~mm} / \mathrm{min}$ and load cell of $25 \mathrm{kgf}$. The test occurred up to $50 \%$ strain. To avoid distortions in the measurements of diameter and height, a millimeter scale was used as a reference, which was positioned next to the test sample during the tests. With a digital camera (Canon SX110), the test was filmed, which was synchronized with the data obtained by the texturometer. Images were obtained every 15 seconds from the film using a software (Windows Movie Maker). The measurement of diameter and height of the specimens was performed using a software of image analysis (ImageTool). Thus it was possible to obtain values of instantaneous radius and height and relate them to the applied force, and the respective values of the effective compressive stress and the coefficient of friction, according to Equation 9.
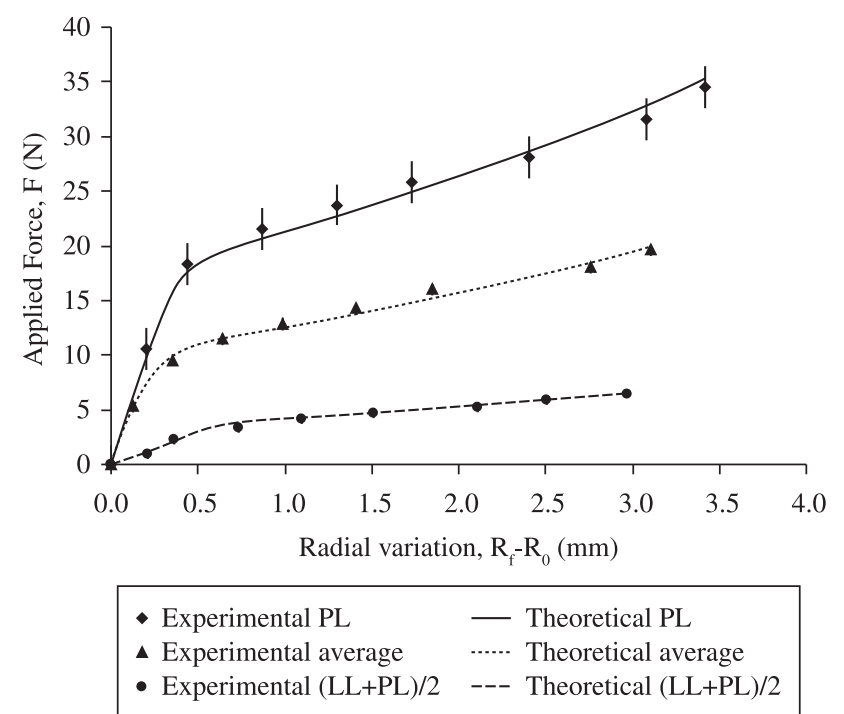

Figure 2. Theoretical curves and experimental points from compression test, A1 clay. $\mathrm{LL}=$ Liquid Limit; $\mathrm{LP}=$ Plastic Limit.

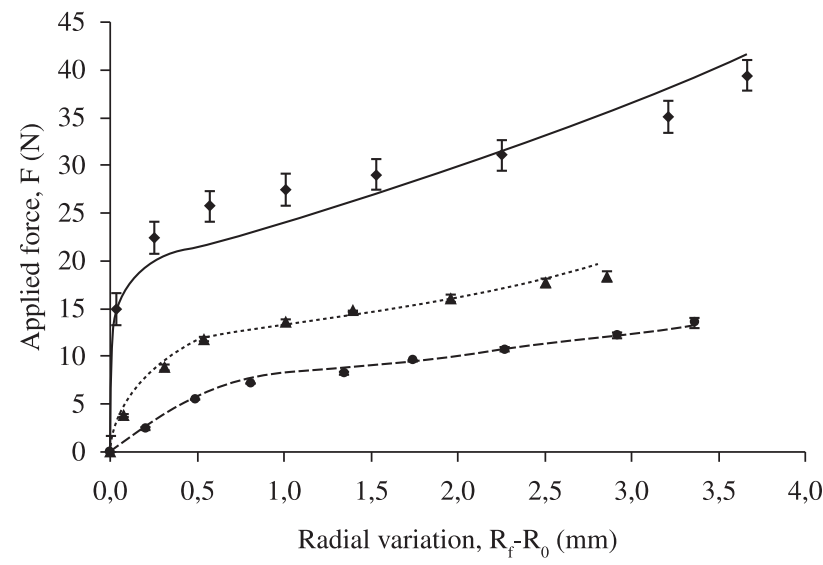

- Experimental PL - Theoretical PL

- Experimental average $\quad$-...-. Theoretical average

- Experimental (LL+PL)/2 --- Theoretical (LL+PL)/2

Figure 3. Theoretical curves and experimental points from compression test, A 2 clay. LL = Liquid Limit; $L P=$ Plastic Limit.

\section{Results and Discussion}

\subsection{Chemical and phase composition}

The results of chemical analysis are presented in Table 1 . The quantification of phases, from XRD and XRF data, was made by rational analysis ${ }^{15}$ which is shown in Table 2 . It can be observed that the main clay mineral present in all three clays is kaolinite. For A3 
clay, this corresponds to $\sim 85 \%$, while the content of quartz, which acts as a non-plastic material, corresponds to $\sim 13 \%$. Due to these values, it is expected that this clay develops higher plasticity when compared to clays A1 and A2, which present respectively lower amounts of kaolinite and higher amounts of quartz.

\subsection{Atterberg's and Pfefferkorn's plasticity index}

The results of tests for determining the Atterberg's (API) and Pfefferkorn's plasticity index (PPI) for the clays are presented in Table 3. For clay A2, it might be noticed that the low API value shows that low variations in moisture may highly affect the plasticity of the clay-water system. PPI, on the other hand, is coherent with Atterberg's, i.e., it is higher for clay A3 and lower for clay A2. A wide variation in plasticity index variation among the clays is observed, which will be useful to investigate the adequacy of the mathematical model in different conditions of plasticity.

\subsection{Compression tests results}

From the load vs. the displacement data generated by the texturometer, the theoretical curves of force vs. variation in radius (according to Equation 9) were found, which are shown in

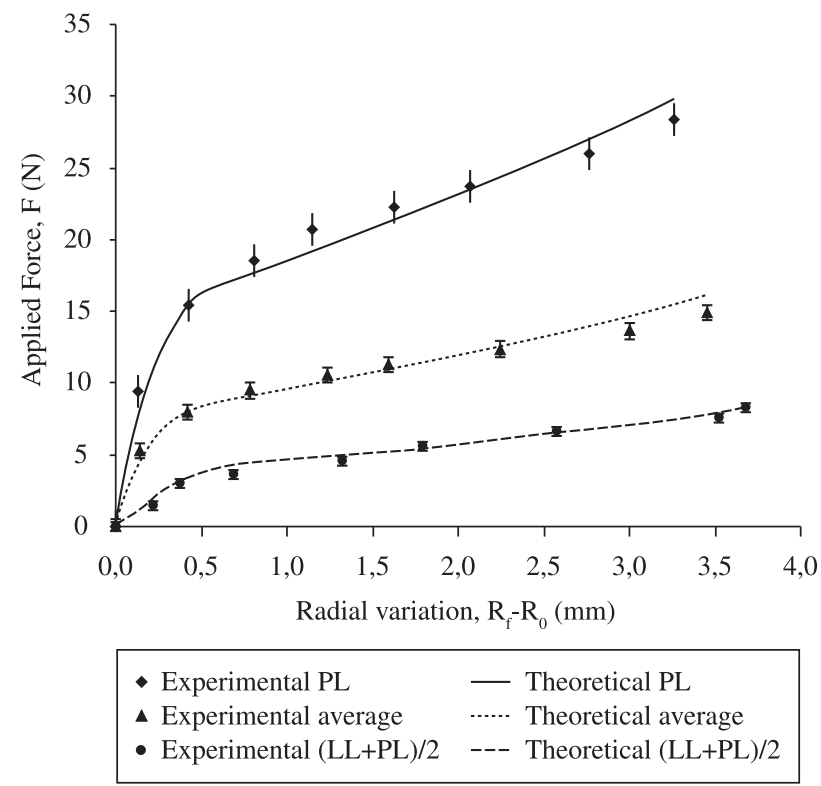

Figure 4. Theoretical curves and experimental points from compression test, A3 clay. LL = Liquid Limit; LP = Plastic Limit.
Figures 2, 3 and 4 for the A1, A2 and A 3 clays, respectively. The shape of the curves as well as the range of measured values is comparable to those obtained by Baran et al. ${ }^{8}$ and Ribeiro et al. ${ }^{5}$, although no fitting model was applied in those cases.

It may be noticed that the experimental points are well fitted by the theoretical curves by choosing appropriate values of effective stress and coefficient of friction. These results are shown in Table 4.

It can be observed that the three clays were similar with respect to the tendency of the curve. The curves area characterized by an elastic region, which is related to the rigidity of the mass against the deformation. Furthermore, it is possible to distinguish an elastic limit, where the clay begins to enter the plastic region, that is, if a force is imposed on it, it retains its shape after removal of that force. This would be the region from which the work of conformation has significant effects.
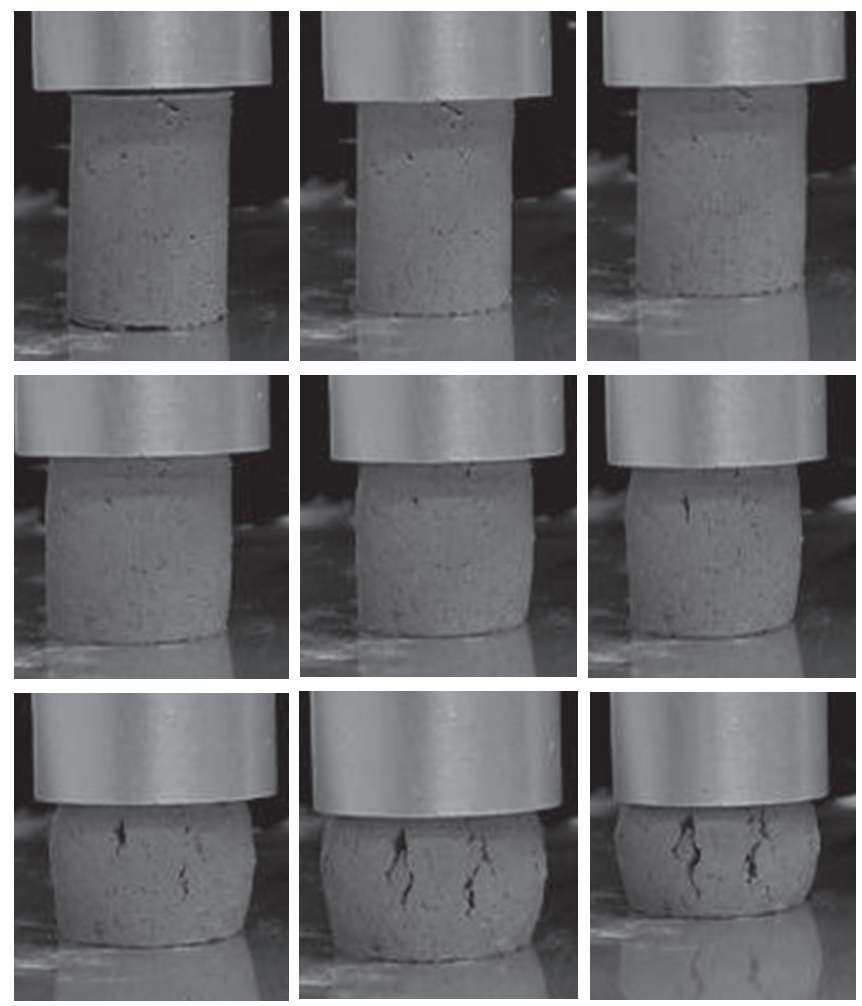

Figure 5. Sequence of typical deformation patterns during compression test (clay A3, 48.9\% moisture).

Table 4. Compression test results.

\begin{tabular}{|c|c|c|c|c|}
\hline Clay & Moisture (\%) & Atterberg parameters* & $\begin{array}{l}\text { Effective stress of compression } \\
(\mathrm{kPa})\end{array}$ & $\begin{array}{l}\text { Coefficient of friction } \\
\text { (non-dimensional) }\end{array}$ \\
\hline \multirow[t]{3}{*}{ A1 } & 43.3 & PL & 71.0 & 0.15 \\
\hline & 48.4 & Average & 42.0 & 0.15 \\
\hline & 54.1 & $(\mathrm{LL}+\mathrm{PL}) / 2$ & 14.3 & 0.15 \\
\hline \multirow[t]{3}{*}{$\mathrm{A} 2$} & 32.4 & PL & 80.0 & 0.15 \\
\hline & 35.3 & Average & 44.0 & 0.15 \\
\hline & 38.6 & $(\mathrm{LL}+\mathrm{PL}) / 2$ & 27.0 & 0.15 \\
\hline \multirow[t]{3}{*}{ A3 } & 42.9 & PL & 62.0 & 0.15 \\
\hline & 48.9 & Average & 32.0 & 0.15 \\
\hline & 56.5 & $(\mathrm{LL}+\mathrm{PL}) / 2$ & 15.5 & 0.15 \\
\hline
\end{tabular}

\footnotetext{
* LL = Liquid Limit; LP = Plastic Limit.
} 


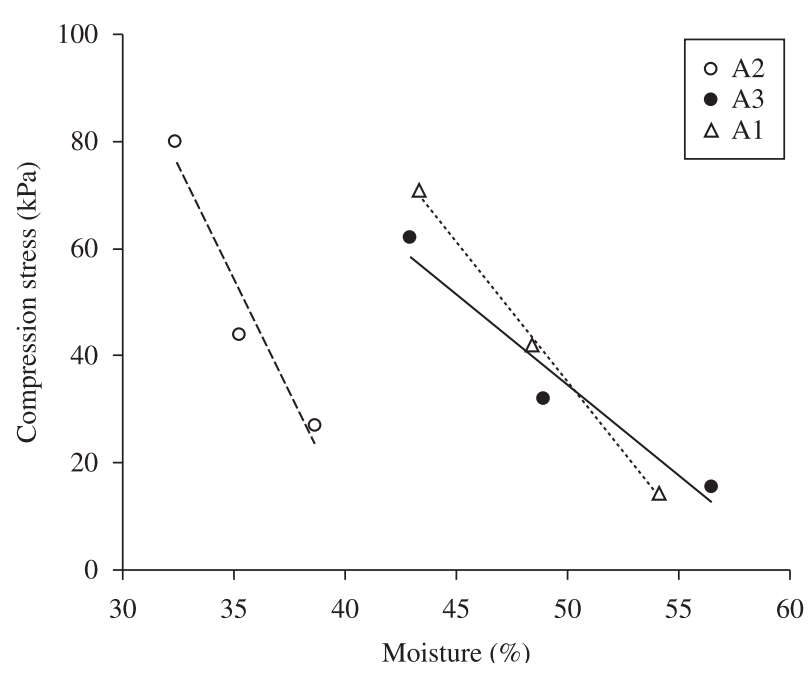

Figure 6. Effective stress of compression and moisture correlation.

Figure 5 shows a typical sequence of events related to the so-called barreling effect during compression test. This effect is attributed to the attrition between the punch and the clay. To avoid errors associated to the measurement, the radius was estimated from the contact surface between the punch and the compact, and at the intermediate height of the sample. An average value was then calculated from those points.

From the results presented in Table 4, a relationship between the effective stress of compression and the moisture can be observed. In Figure 6 it can be seen that there is a good correlation between these two parameters within the same type of clay. However, there was no correlation between these parameters, when different clays are compared. This can be explained by differences in chemical and phase composition of the clays, which develop different plasticity despite the similar moisture content.

The plasticity measured from compression tests allows that the results obtained by the mathematical modeling may be applied to describe the behavior of a clay during shaping processes such as extrusion ${ }^{16}$ or pressing.

\section{Conclusions}

In this work, the compression test to characterize the plasticity of clay-water systems was applied. This type of test may serve as a complement to Atterberg's and Pfefferkorn's traditional tests, since it allows more precise information, is less operator-dependent in performing the tests and also some characteristics are obtained for the design of the process to which the clays will be submitted.

It was observed that there is a correlation between the effective stress of compression and moisture present in the mass. This condition was valid only within each group of clay, since equal humidity may produce different results in clays with different compositions.
Although the coefficient of friction is a dynamic variable depending on the test and process parameters, in this work it was considered constant, due to the difficulty of its formulation. New studies may be performed to observe if there is a correlation between the phases present in the clays and the coefficient of friction. A quantification of this influence should be included in a further modeling in order to optimize the processing parameters in accordance with the mass formulation.

\section{Acknowledgments}

We wish to thank Conselho Nacional de Desenvolvimento Científico e Tecnológico (CNPq) for supporting this work.

\section{References}

1. Reed JS. Principles of Ceramic Processing. $2^{\text {nd }}$ ed. New York: Wiley; 1995.

2. Barba A, Beltrán V, Feliu C, Garcia J, Ginés F, Sánchez E et al. Materias Primas para la Fabricación de Soportes de Baldosas Cerámicas. Castellón: AICE/ITC; 1997.

3. Händle F (Ed.). Extrusion in Ceramics. Berlin: Springer; 2007.

4. Jefferson I and Rogers CDF. Engineering Geology. 1998; 49(2):95-109.

5. Ribeiro MJ, Ferreira JM and Labrincha JA. Plastic behaviour of different ceramic pastes processed by extrusion. Ceramics International. 2005; 31(4):515-519.

6. Bergaya F, Theng B and Lagaly G (Ed.). Handbook of Clay Science. New York: Elsevier; 2006.

7. Amorós JL, Sánchez E, García-Ten J, Sanz V and Monzó M. Manual para el Control de la Calidad de Materias Primas Arcillosas. Castellón: Instituto de Tecnología Cerámica; 1998.

8. Baran B, Erturk T, Sarikaya Y and Alemdaloglu T. Workability test method for metals applied to examine a workability measure (plastic limit) for clays. Applied Clay Science. 2001; 20(1-2):53-63.

9. Campos LFA, Macedo RS, Kiyohara PK and Ferreira HC. Características de plasticidade de argilas para uso em cerâmica vermelha ou estrutural. Cerâmica. 1999; 45(295):140-145.

10. Al-Qureshi HA, Galiotto A and Klein AN. On the mechanics of cold die compaction for powder metallurgy. Journal of Materials Processing Technology. 2004; 166(1):135-143.

11. Avitzur B. Metal Forming: Process and Analysis. New York: McGrawHill; 1968.

12. Associação Brasileira de Normas Técnicas - ABNT. NBR 6459. Determinação do Limite de Liquidez de Solos. Rio de Janeiro: ABNT; 1984.

13. Associação Brasileira de Normas Técnicas - ABNT. NBR 7180. Determinação do Limite de Plasticidade de Solos. Rio de Janeiro: ABNT; 1984

14. Associação Brasileira de Normas Técnicas - ABNT. NBR 6457. Amostras de Solo Preparação para Ensaios de Compactação e Ensaios de Caracterização. Rio de Janeiro: ABNT; 1986.

15. Coelho C, Roqueiro N and Hotza D. Rational mineralogical analysis of ceramics. Materials Letters, 2002; 52(6):394-398.

16. Andrade FA, Al-Qureshi HÁ and Hotza D. Modelo matemático aplicado ao processo de extrusão de argilas. Cerâmica, 2010; in press. 
